\title{
Cysteine Borylation in Unprotected Peptides
}

Mary A. Waddington, ${ }^{1}$ Alice Zheng, ${ }^{2}$ Julia M. Stauber, ${ }^{1}$ Elamar Hakim Moully, ${ }^{1}$ Liban M. A. Saleh, ${ }^{1}$ Petr Král, ${ }^{2,3,4,{ }^{*}}$ Alexander M. Spokoyny ${ }^{1,5, *}$

${ }^{1}$ Department of Chemistry and Biochemistry, University of California, Los Angeles, 607 Charles E. Young Drive East, Los Angeles, CA 90095, United States

${ }^{2}$ Department of Chemistry, University of Illinois at Chicago, Chicago, IL 60607, United States

${ }^{3}$ Department of Physics, University of Illinois at Chicago, Chicago, IL 60607, United States

${ }^{4}$ Department of Biopharmaceutical Sciences, University of Illinois at Chicago, Chicago, IL 60612, United States

${ }^{5}$ California NanoSystems Institute (CNSI), University of California, Los Angeles, 570 Westwood Plaza, Los Angeles, CA 90095, United States

\begin{abstract}
:
Synthetic bioconjugation at cysteine (Cys) residues in peptides and proteins has emerged as a powerful tool in chemistry. Soft nucleophilicity of the sulfur in Cys renders an exquisite chemoselectivity with which various functional groups can be placed onto this residue under benign conditions. While a variety of reactions have been successful at producing Cys-based bioconjugates, the majority of these feature sulfur-carbon bonds. We report Cys-borylation, wherein a benchtop stable $\mathrm{Pt}(\mathrm{II})$-based organometallic reagent can be used to transfer a boron-rich cluster onto a sulfur moiety in unprotected peptides forging a boron-sulfur bond. Discovered Cysborylation proceeds at room temperature and is tolerant to a variety of functional groups present in complex polypeptides. The resultant bioconjugates show no additional toxicity compared to their Cys aryl-based congeners. Finally, we demonstrate how the developed Cys-borylation can enhance the proteolytic stability of the produced peptide bioconjugates while maintaining the binding affinity to a protein target.
\end{abstract}


Synthetic bioconjugation has emerged as a powerful tool towards understanding and altering biomolecular interactions. Mimicking the post-translational modifications ubiquitous to natural biological systems, a variety of C-S, C-O, C-N and C-C bond forming reactions have been previously reported ${ }^{1,2}$. These synthetic tools have been used to install handles on biomolecules for applications ranging from imaging ${ }^{3,4}$ to enhancement of therapeutic efficacy $y^{5,6}$.

Cysteine (Cys) residues in proteins and peptides represent a historically attractive site for synthetic bioconjugation development owing to its soft nucleophilicity and low natural abundance which contributes to its capacity to undergo site-directed mutagenesis and subsequent selective modification ${ }^{7}$. These chemoselective Cys conjugations can be achieved through both metal free and recently developed metal-mediated routes (Figure 1A). Conjugate addition to Michael acceptors (e. g., maleimides and vinyl sulfones ${ }^{1,2}$ ) as well as $\mathrm{S}_{\mathrm{N}} 2$ reactions with alkyl electrophilic centers $^{1,2}$ represent the most common metal-free transformations; however, a number of noteworthy other alkylation and arylation strategies have been reported ${ }^{1,7,10-16}$. Recently, transition metal-mediated C-S bond forming reactions have attracted considerable attention due to the rapid kinetics, mild reaction conditions and high functional group tolerance often associated with these metal-based transformations ${ }^{1,17}$ (Figure 1A). For example, Buchwald, Pentelute and coworkers demonstrated a unique approach towards chemoselective Cys modification via arylation using well-defined and benchtop-stable Pd-based organometallic reagents ${ }^{17}$. The reaction conditions were amenable to covalent linkage of fluorescent and affinity tags, drug molecules and handles for further conjugation. This concept was also demonstrated using a stochiometric $\mathrm{Au}(\mathrm{I} / \mathrm{III})$ platform $^{18,19}$ as well as several notable catalytic strategies ${ }^{15,24}$. 


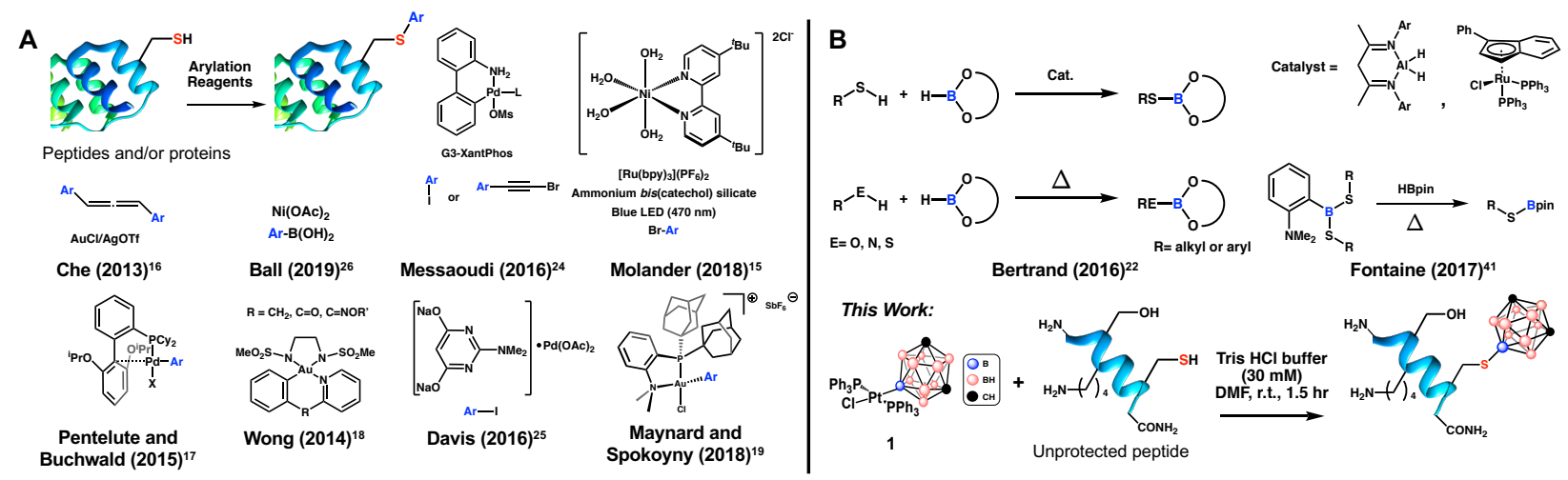

Figure 1 A: Summary of selective C-S bond forming reactions for bioconjugation of unprotected peptides and proteins. Metal-mediated strategies result in thiol arylation with the transferred group highlighted in blue. B: Summary of selective S-B bond forming reactions.

While a large breadth of chemoselective C-S bond forming bioconjugations have been reported, analogous transformations resulting in the formation of boron-sulfur bonds (B-S) are conspicuously absent. While substrates containing free thiols have been borylated through metalmediated and metal-free routes (Figure 1B), these methods generally lack selectivity for thiols over other competing nucleophilic centers which is a key prerequisite for successful bioconjugation reactions. These include thiol borylation reactions using pinacol, 9-BBN or catechol borane and either aluminum- ${ }^{20}$ or ruthenium-based ${ }^{21}$ catalysts, where alcohols and amines can also be competent substrates for borylation under similar catalytic conditions (Figure 1B). Similar selectivity issues arise in uncatalyzed borylation of thiols as evidenced by the work of Bertrand and co-workers ${ }^{22}$. In their recent elegant work, Fontaine et al. ${ }^{23}$ used frustrated Lewis pairs to improve the selectivity of the sulfur borylation of aromatic and aliphatic thiol substrates; however, the use of relatively high temperatures and nonpolar solvents preclude the application of this chemistry towards Cys containing biomolecules.

Similarly to recently reported transition metal-mediated arylation strategies which augmented the bioconjugation landscape by producing Cys-Ar hybrid systems (Fig. 1A) with fundamentally new propeties ${ }^{16-19,24-26}$, we envisioned how analogous borylation reactions might 
further expand the biomolecular toolbox. As there are no existing methods competent towards peptide and protein borylation with tricoordinate boron substrates, we hypothesized that these limitations could be overcome by using a different source of boron-based fragment. Icosahedral boranes represent a promising platform to probe this hypothesis given their three-dimensional delocalized aromaticity ${ }^{27-33}$ analogous to the carbon-based aromatic molecules previously employed for bioconjugation. Here, we show that $\mathrm{Pt}(\mathrm{II})$ complex $^{34}$ supported by a boron bound carboranyl cluster (1) is capable of chemoselective Cys borylation across multiple unprotected peptide substrates to generate the first B-S bond linkages post-synthetically, which was a previously inaccessible modality in bioconjugation. Importantly, the borylated peptides were stabile towards excess base, acid and external thiol and did not display any appreciable toxicity up to $50 \mu \mathrm{M}$ in cell culture. In addition to providing a new chemical connectivity, the developed Cys borylation offers new opportunities in areas of multivalent binding and tuning of ligand-receptor interactions in biomolecular targeting.

\section{Results and Discussion}

To test whether one can use boron-cluster supported organometallic reagents for successful Cys borylation, we subjected model peptide $\mathrm{H}_{2} \mathrm{~N}-\mathrm{VKGALGVCG}-\mathrm{CONH}_{2}$ (2a) with 1 under various conditions. Nearly quantitative conversion to a peptide containing a mass consistent with a Cys-borylated peptide was observed within $1.5 \mathrm{~h}$ when $2 \mathrm{a}(5 \mathrm{mM})$ was treated with 1.2 equivalents of 1 at $25{ }^{\circ} \mathrm{C}$ in the presence of Tris $\bullet \mathrm{HCl}$ buffer $(30 \mathrm{mM})$ in dimethylformamide (DMF) as assessed by LC-MS analysis of the crude reaction mixture (Figure 2A). In order to verify that the reaction conditions were selective for Cys over other nucleophiles within the model peptide substrate, tandem MS/MS of Cys-borylated peptide 2b was conducted. Fragmentation patterns support exclusive Cys borylation (Figure S18). 


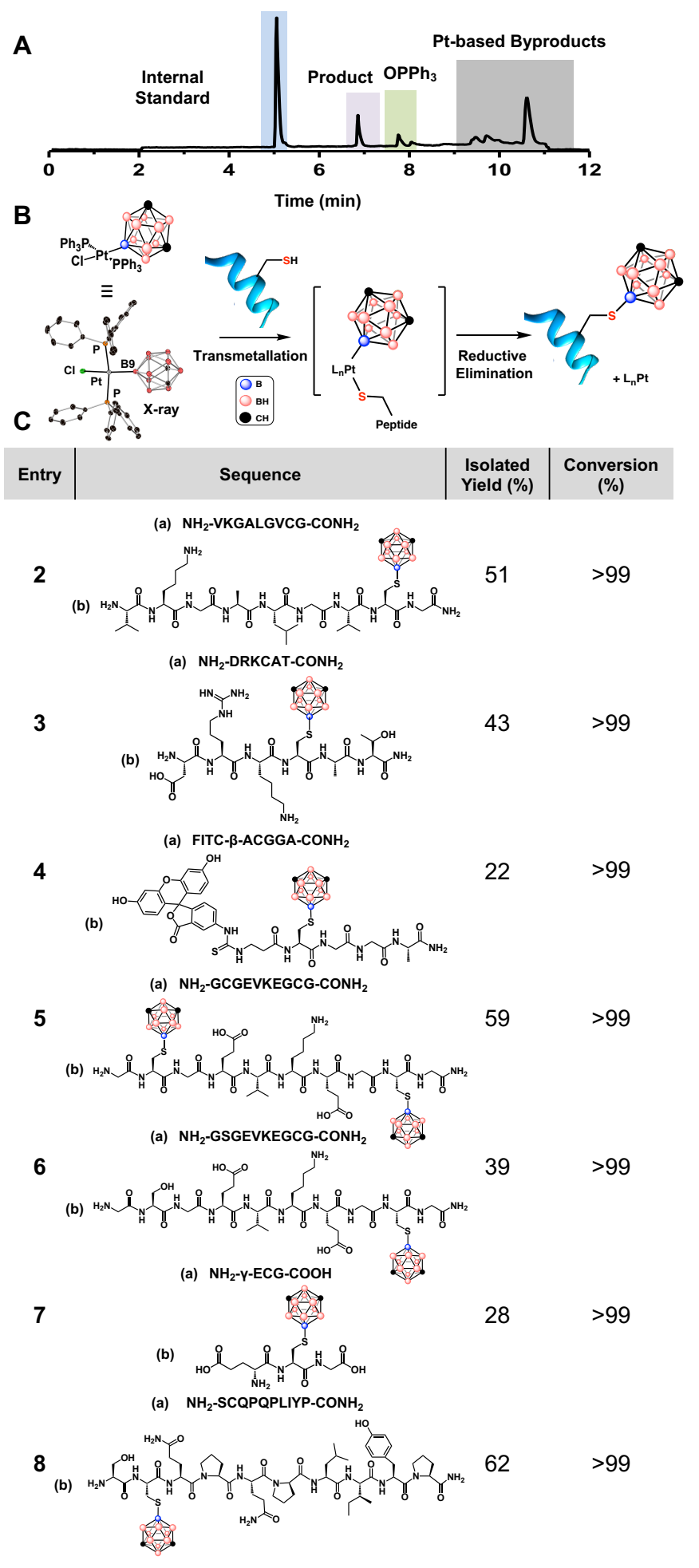

Figure 2 A: Representative LC trace collected after 1 (1.2 equiv) and $\mathrm{H}_{2} \mathrm{~N}-\mathrm{VKGALGVCG-}$ $\mathrm{CONH}_{2}(5 \mathrm{mM})$ were allowed to react for $1.5 \mathrm{~h}$ at $25{ }^{\circ} \mathrm{C}$ in the presence of Tris $\bullet \mathrm{HCl}$ buffer $(30$ $\mathrm{mM}$ ) in dimethylformamide (DMF). Internal standard was produced through alkylation of $\mathrm{H}_{2} \mathrm{~N}-$ VKGALGVCG-CONH 2 (see SI section I). B: Peptide substrate scope with isolated yields (\%) and conversion $(\%)$. 
Analogous to arylation bioconjugation involving Pd-based reagents ${ }^{17}$, we propose this chemoselectivity arises from the transmetallation of the soft nucleophilic Cys sulfur residue that has a high propensity towards binding a $\mathrm{Pt}(\mathrm{II})$ metal center ${ }^{35,36}$. A subsequent reductive elimination process affords Cys-borylated peptide and Pt-based byproducts (Figure 1B). Importantly, this process proceeds efficiently despite the carboranyl group being significantly more sterically encumbering than the previously demonstrated aryl-based species ${ }^{27}$ ultimately highlighting the advantages of the organometallic approach used.

To ensure generality of this method, we then applied the reaction conditions used to generate 2b towards other peptide sequences (Figure 2C). Across all peptide substrates tested (entries 2-7), we observed nearly quantitative conversion towards the corresponding borylated product with isolated yields ranging from 22-59\% after HPLC purification (Figure 2C). Furthermore, the borylation reaction conditions were tolerant to the common labeling dye, fluorescein isothiocyanate (FITC) attached to the N-terminus of the peptide chain despite the presence of a thiourea linkage which could also serve as a chelating ligand towards the metal center (entry 4). Even though carboranyl ligands are sterically bulky, diborylation of a peptide containing two Cys residues is possible; nearly quantitative conversion of $\mathbf{5 a}$ to $\mathbf{5 b}$ was observed under the optimized reaction conditions (entry 5). Importantly, only monoborylation was observed when 6a, which contains identical residues as $\mathbf{5 a}$ except one Cys is mutated to a serine residue, was subjected to identical treatment (Figures S11 and S12). Overall, the borylation selectivity towards Cys thiols in unprotected peptides using $\mathbf{1}$ as a transfer reagent mirrors the selectivity of both $\operatorname{Pd}(\mathrm{II})$ and $\mathrm{Au}(\mathrm{III})$ organometallic Cys arylation reagents ${ }^{17,19}$. 
After assuring Cys-borylation was successful across multiple thiol containing peptides, we decided to perform an additional robustness screen for additional reagents that are often used in bioconjugation reactions on peptides. Diluting the DMF reaction mixture with water did not diminish conversion up to $25 \%$ water when model peptide $\mathrm{H}_{2} \mathrm{~N}-\mathrm{VKGALGVCG-CONH} 2$ (2a) was treated with 1 . Reaction mixtures exceeding $25 \%$ water resulted in a significant reduction in conversion, likely due to the poor solubility of 1 in water (Figure S15). Further, the bioconjugation was compatible with a common denaturing agent guanidine $\bullet \mathrm{HCl}(3 \mathrm{M}$, Figure S16A), suggesting the organometallic complex $\mathbf{1}$ is stable under highly ionic conditions on the timescale of the reaction. Further, addition of Tris(2-carboxyethyl)phosphine hydrochloride (TCEP HCl), a common reducing agent for disulfide moieties in biomolecules, does not significantly alter the conversion efficiency of the reaction (Figure S16B) indicating excess phosphine does not shut down the reactivity of $\mathbf{1}$ on the timescale of the reaction.

In order to probe the local environment of the carboranyl cluster on the purified Cysborylated peptides using ${ }^{11} \mathrm{~B}$ NMR spectroscopy, we decided to apply the borylation reaction to a peptide substrate with a low molecular weight to increase the signal to noise outcome of this experiment. Commercially available L-glutathione (7a) was thus chosen for these studies. Successfully Cys-borylated glutathione (7b) was subjected to a routine HPLC purification followed by ${ }^{11} \mathrm{~B}$ NMR spectroscopic analysis. A distinct singlet resonance was observed at $2 \mathrm{ppm}$ along with multiple broad doublets in an integral ratio of 1:9 consistent with the splitting pattern of a B(9)-substituted, intact $m$-carboranyl cluster (Figure S19A). Importantly, the ${ }^{11} \mathrm{~B}\left\{{ }^{1} \mathrm{H}\right\}$ NMR spectrum of the same sample indicates that the doublets observed stem from the ${ }^{11} \mathrm{~B}-{ }^{1} \mathrm{H}$ coupling and the resonance at $2 \mathrm{ppm}$ is consistent with a ${ }^{11} \mathrm{~B}$ atom that is not bound to a ${ }^{1} \mathrm{H}$ nucleus (Figure S19B). Based on these observations and previously reported NMR spectroscopy data collected on 
$B_{9}$ substituted carborane thiols and thioether species ${ }^{34}$, the resonance at $2 \mathrm{ppm}$ was assigned to the ${ }^{11} \mathrm{~B}(9)$-S nucleus on the intact $m$-carborane cluster attached to the peptide. Finally, IR spectroscopy was used to further corroborate structural elements of $\mathbf{7 b}$. A diagnostic stretching band ascribed to the B-H bond vibrations on the cluster $\left(2532-2681 \mathrm{~cm}^{-1}\right)$ was observed in samples of $7 \mathbf{b}$ and was absent in 7a when both samples were analyzed as powders by ATR IR spectroscopy (Figure S20). Additional evidence that Cys thiol conjugation had proceeded is provided by the disappearance of a free S-H stretch $\left(2454-2545 \mathrm{~cm}^{-1}\right)$ in the spectrum of $7 \mathbf{b}$ compared to the spectrum of $7 \mathbf{a}$ (Figure S20). The spectroscopic techniques outlined above unequivocally confirm successful B-S bond formation using 1 and unprotected peptides containing Cys residues.

We next evaluated the stability of the B-S bond in $\mathbf{7 b}$ as a model Cys-borylated peptide. Specifically, we assessed the fidelity of $\mathbf{7 b}$ towards an acidic environment with a $\mathrm{pH}$ of 2.3 as this value falls within the normal $\mathrm{pH}$ range for stomach acid $(\mathrm{pH}=1-3)^{37}$. Sample of $7 \mathbf{b}(0.05 \mathrm{mM})$ was incubated in the presence of hydrochloric acid $(5 \mathrm{mM})$ at $25^{\circ} \mathrm{C}$ and $37^{\circ} \mathrm{C}$ for 72 hours (Figure 3A).
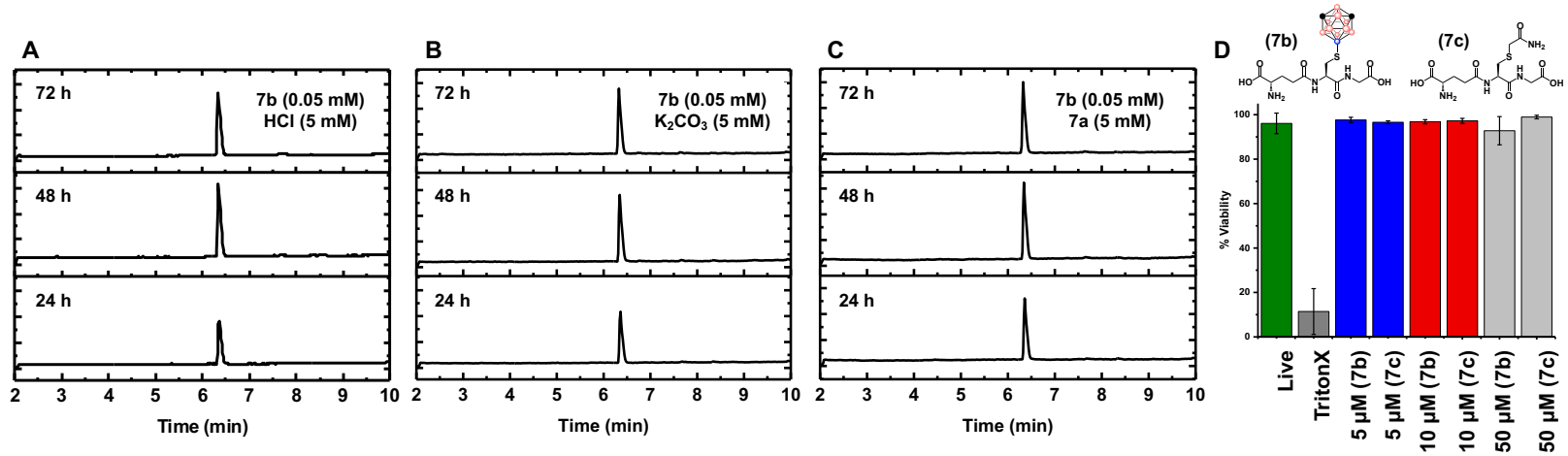

Figure 3: LC-MS traces of $\mathbf{7 b}$ incubated with 100 excess A: hydrochloric acid B: potassium carbonate and C: 7a after 24, 48 and 72 hrs (See SI Section VI for full details). D: The \% cell viability assessed after four-hour incubation of $\mathbf{7 b}$ and $\mathbf{7} \mathbf{c}$ with Chinese Hamster Ovarian (CHO) cells at $5 \mu \mathrm{M}, 10 \mu \mathrm{M}$ and $50 \mu \mathrm{M}$ concentration of analyte. 
No fragmentation was observed by LC-MS analysis of the mixture, indicating the S-B bond within 7b stay intact at $\mathrm{pH} 2.3$ under the timeframe of the experiment. After assessment of stability towards acid, we probed the resistance of $\mathbf{7 b}$ towards basic conditions. While intracellular $\mathrm{pH}$ remains close to neutral, published reports suggest alkaline microenvironments could be important in cellular signaling ${ }^{38}$. To rigorously determine the tolerance of Cys-borylated peptides towards base, we incubated $\mathbf{7 b}$ at $\mathrm{pH} 11$, a significantly more alkaline environment than would be anticipated for human cells. Sample of $7 \mathbf{b}(0.05 \mathrm{mM})$ was incubated in the presence of potassium carbonate $(5 \mathrm{mM})$ at $25^{\circ} \mathrm{C}$ and $37{ }^{\circ} \mathrm{C}$ for 72 hours. No fragmentation was observed by LC-MS analysis of the mixture, indicating the stability of the S-B bond within 7b (Figure 3B). Finally, we evaluated the stability of $\mathbf{7 b}$ towards external thiol source. Glutathione (7a) was selected as it represents the most abundant non-protein source of thiol in eukaryotic cells with intracellular concentrations ranging from $1-10 \mathrm{mM}^{39}$. Sample of $7 \mathbf{b}(0.05 \mathrm{mM})$ was incubated in the presence of $7 \mathbf{a}(5 \mathrm{mM})$ at $25^{\circ} \mathrm{C}$ and $37^{\circ} \mathrm{C}$ for 72 hours. No fragmentation was observed by LC-MS analysis of the mixture, indicating the S-B bond within $\mathbf{7 b}$ does not undergo thiol exchange chemistry in the presence of large excess of external thiol (Figure 3C). Importantly, this stability towards external thiol is in contrast to classical Cys-based bioconjugation tools that employ Michael acceptors which often undergo retro-Michael addition when subjected to the presence of other thiol substrates ${ }^{1}$. Altogether, the stability of $\mathbf{7 b}$ demonstrated herein suggests the S-B bond within Cys-borylated peptides can be bioorthogonal towards harsh biological milieu.

After, confirming the stability of these constructs, we decided to evaluate the toxicity of Cys-borylated peptides towards Chinese Hamster Ovarian (CHO) cells using $\mathbf{7 b}$ as a model peptide. As Pt(II) complexes have well described toxicity ${ }^{40}$, we first assessed the efficiency of the purification method towards removing all metal-based byproducts. ICP-AES analysis of $\mathbf{7 b}$ 
purified by reversed-phase HPLC indicated $>99.9 \%$ platinum content had been removed (See SI Section II, Figure S1). Four-hour incubation of pure, isolated $\mathbf{7 b}$ with $\mathrm{CHO}$ cells resulted in no appreciable toxicity up to $50 \mu \mathrm{M}$ (Figure 3D). As a control sample, acetamide-glutathione (7c) was also incubated under the same conditions and exhibited no appreciable toxicity up to $50 \mu \mathrm{M}$ (Figure 3D). The similar cell viability profiles for Cys-boryl glutathione and Cys-acetamide glutathione suggest no inherent cytotoxicity is added through forging a B-S bond by appending a boron cluster to unprotected peptides.

Few post translational modifications are competent towards the chemoselective transfer of bulky substrates containing large cone angles directly at amino acid sites. A rare example was demonstrated independently by both Park $^{41}$ and Davis ${ }^{42}$ who prepared tert-Leu residues via dehydroalanine, however, the bioconjugates formed are racemates. The present strategy offers the first organometallic-based route towards unprotected peptide modification with a highly bulky moiety that does not alter the local stereochemistry, affording unique opportunities to assess the role steric encumbering at amino acid sites has upon downstream peptidic properties. Specifically, we probed the capacity of Cys-boryl peptides to participate in receptor binding by titrating $\mathbf{7 b}$ as a model peptide to $\beta$-cyclodextrin, a sugar macrocycle which is widely used in catalysis, analytical separation and solubilization ${ }^{43}$. Isothermal titration calorimetry (ITC) experiment was carried out where peptide $7 \mathbf{b}(10 \mathrm{mM})$ was titrated to $\beta$-cyclodextrin $(0.25 \mathrm{mM})$ in an aqueous buffered solution at $\mathrm{pH} 3.4$ revealing a binding stoichiometry $(\mathrm{N}=1)$ and an association constant $\left(K_{a}=1.47\right.$ $\left.\mathrm{x} 10^{4} \pm 500 \mathrm{M}^{-1}\right)($ Figure $4 \mathrm{~A}$ and B). The approximated binding stoichiometry of $\mathrm{N}=1$ is consistent with a 1:1 $\mathbf{7 b} \subset \beta$-cyclodextrin inclusion complex promoted by the chaotropic properties of the cluster cage inserting into the macrocycle cavity ${ }^{44,45}$. The observed $K_{a}$ is an order of magnitude higher than was observed between unmodified $m$-carborane and $\beta$-cyclodextrin when measured 
by a displacement binding technique ${ }^{46}$, which could be attributed to the enhanced solubility of $\mathbf{7 b}$ over unmodified $m$-carborane in aqueous media. Cys-modified S-phenyl glutathione (7d, Figure 4C) and 7a (Figure 4D) were used as controls and did not exhibit any appreciable binding affinity to $\beta$-cyclodextrin by ITC under the same measurement conditions. These controls highlight the receptor specificity and the capacity of borylation to engender a unique binding profile between $7 \mathbf{b}$ and a macrocyclic sugar.
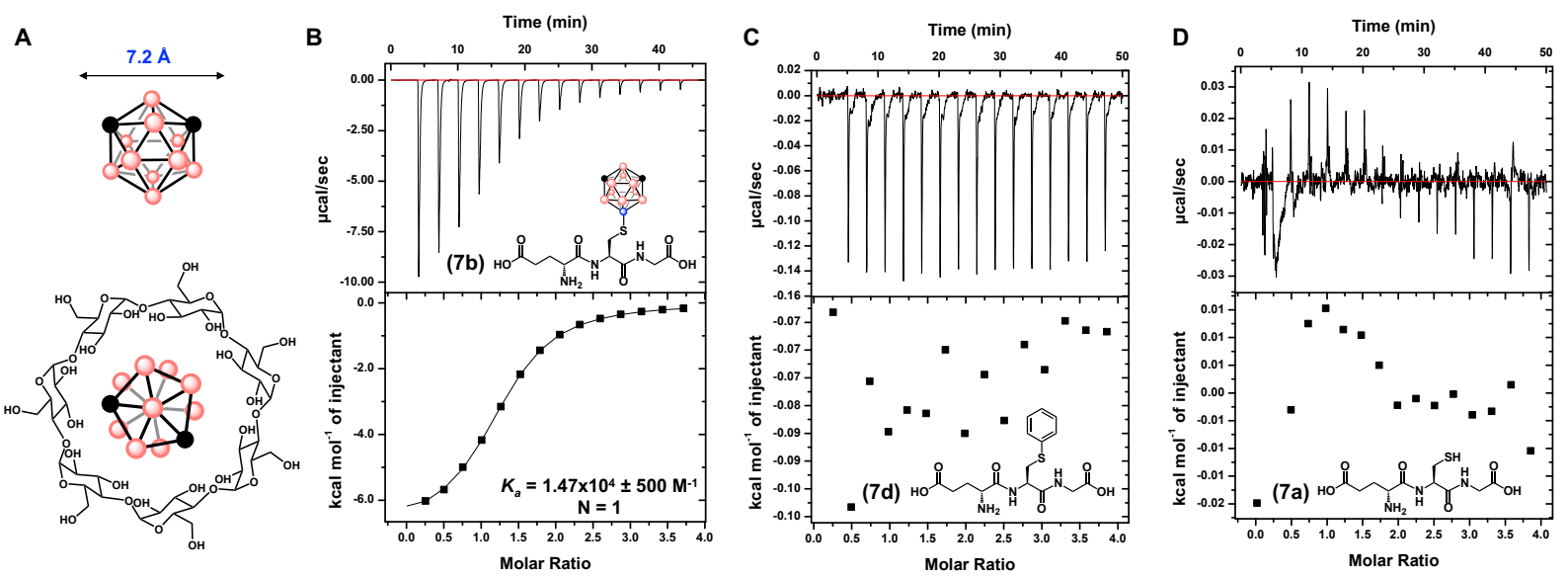

Figure 4 A: Representation of the inclusion complex formed between $m$-carborane and $\beta$ cyclodextrin ${ }^{53,54}$. B: ITC binding plot for carboranylated glutathione and $\beta$-cyclodextrin to yield an association constant $\left(K_{a}=1.47 \times 10^{4} \pm 500 \mathrm{M}^{-1}\right)$ and binding stoichiometry $(\mathrm{N}=1)$. C: ITC binding plot for phenyl-glutathione and $\beta$-cyclodextrin. D: ITC binding plot for unmodified glutathione and $\beta$-cyclodextrin.

Finally, we evaluated the stability of Cys-boryl peptides towards a broadly acting serine protease, Proteinase K. Specifically, Cys-boryl peptide $\mathbf{2 b}$ was chosen as a model substrate owing to the many aliphatic amino acid residues in the sequence which are cleavable by Proteinase $\mathrm{K}^{46}$. We envisaged $\mathbf{2 b}$ might resist the activity of Proteinase $\mathrm{K}$ to a higher degree than $\mathbf{2 a}$ owing to the steric hindrance of the carboranyl group positioned proximally to the peptide backbone thereby blocking access to cleavable residues. To test this hypothesis, $\mathbf{2} \mathbf{b}$ was incubated with Proteinase $\mathrm{K}$ for $5 \mathrm{~min}$ at $60{ }^{\circ} \mathrm{C}$ in the presence of Tris $\bullet \mathrm{HCl}$ buffer $(50 \mathrm{mM}, \mathrm{pH}=8.2)$ and $\mathrm{CaCl}_{2}(5 \mathrm{mM})$. After 
treatment, $45 \pm 1 \% \mathbf{2 b}$ remained intact as assessed by integration of the peak compared to integration of the internal standard (Table 1, Entry G). In contrast, no intact peptide remained when 2a was subjected to the same reaction conditions (Table 1, Entry A), indicating Cysborylation is competent towards inhibiting the action of Proteinase $\mathrm{K}$ within this timeframe. We then subjected Cys-aryl peptide $2 \mathrm{c}$ to Proteinase $\mathrm{K}$ treatment for $5 \mathrm{~min}$ at $60{ }^{\circ} \mathrm{C}$ in the presence of buffer $(50 \mathrm{mM})$ and $\mathrm{CaCl}_{2}(5 \mathrm{mM})$ (Table 1, Entry D). No intact peptide was observed under these conditions, suggesting inhibition of proteolytic degradation is unique to Cys-boryl conjugates compared to aryl-based congeners.

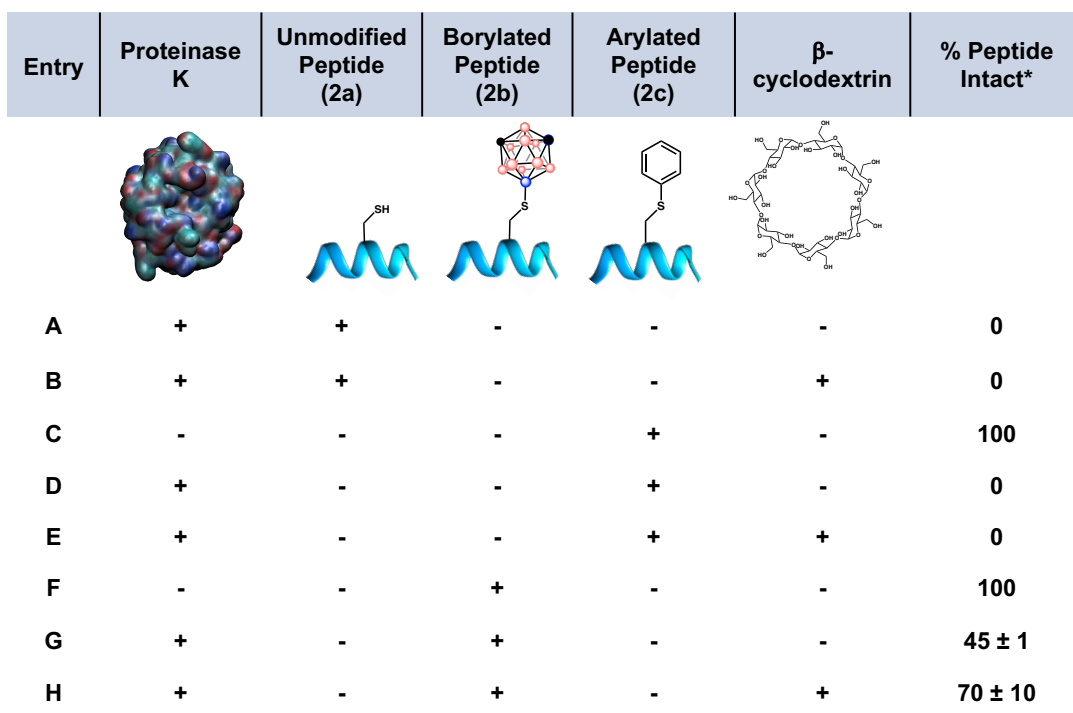

Table 1: The reaction schemes and the observed corresponding degradation of $2 \mathbf{a}, \mathbf{2 b}$ and $\mathbf{2 c}$ with Proteinase $\mathrm{K}$ under various conditions.

To extend the steric hindrance surrounding the Cys moiety, we next subjected the $\mathbf{2} \mathbf{b} \subset \beta$ cyclodextrin inclusion complex to Proteinase K treatment (see SI for further details on the characterization of $\mathbf{2} \mathbf{b} \subset \beta$-cyclodextrin). The complex $\mathbf{2 b} \subset \beta$-cyclodextrin was heated for $5 \mathrm{~min}$ at $60{ }^{\circ} \mathrm{C}$ in the presence of buffered Proteinase $\mathrm{K}$ (Tris $\left.\bullet \mathrm{HCl}, 50 \mathrm{mM}, \mathrm{pH}=8.2\right)$ and $\mathrm{CaCl}_{2}(5 \mathrm{mM})$. After this treatment, $70 \pm 10 \%$ intact $\mathbf{2 b}$ remained (Table 1, Entry H). Importantly, incubation of 2a and $\mathbf{2 c}$ with $\beta$-cyclodextrin prior to treatment with the same Proteinase $\mathrm{K}$ reaction conditions 
resulted in full degradation (Table 1, Entries B and E), indicating the presence of $\beta$-cyclodextrin alone is insufficient towards inhibiting degradation. Overall, these experiments suggest that Cysborylation can render peptides more proteolytically stable.

Molecular dynamics (MD) simulations of were used to elucidate possible nature of the stability enhancement towards proteolysis. MD simulations of $\mathbf{2 a}, \mathbf{2} \mathbf{b}$ and $\mathbf{2 c}$ with Proteinase K demonstrate stable binding of all peptides to the reported substrate recognition site ${ }^{47}$ by two segments, Gly100 to Tyr104 and Ser132 to Gly136 (Movies 1-3). A second binding pocket (Figure 5A) formed by Gly134-Gly135-Gly-136 and Gly160-Asn161-Asn162 was identified for the unique capacity to bind the carborane of $\mathbf{2} \mathbf{b}$ as a result of $\mathrm{B}-\mathrm{H} \cdots \mathrm{H}-\mathrm{N}$ dihydrogen ${ }^{48}$ and $\mathrm{C}$ $\mathrm{H} \cdots \mathrm{O}$ or $\mathrm{C}-\mathrm{H} \cdots \mathrm{N}$ hydrogen bonding interactions ${ }^{27}$ (Figures 5B, S36-37).
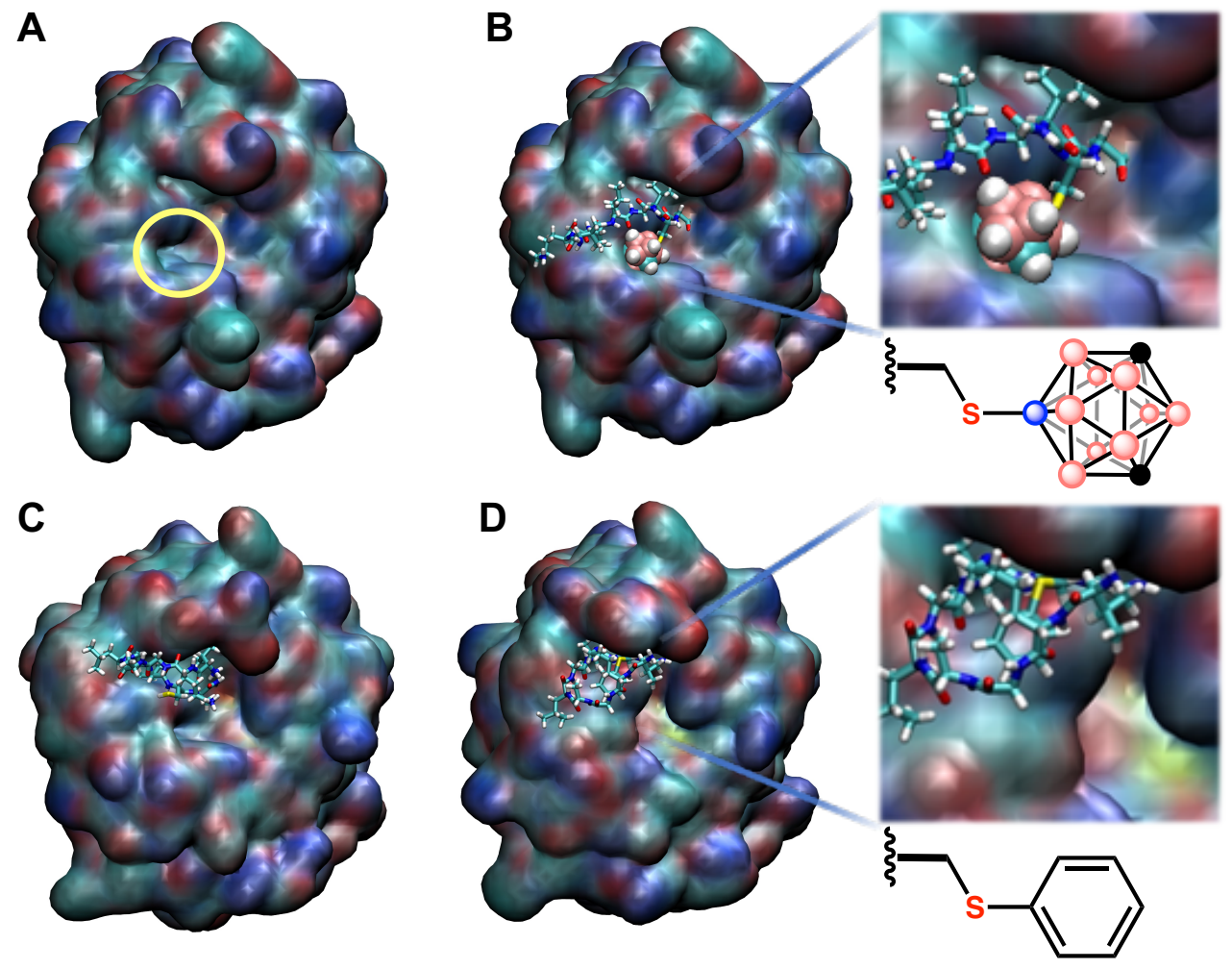

Figure 5: Molecular dynamics simulations of A: the secondary binding pocket identified as an important docking site B: $2 \mathbf{b}$ binding with Proteinase K, C: 2 a binding with Proteinase K and D: 2c binding with Proteinase K. All simulations are represented using QuickSurf modeling in VMD after 120 ns of equilibration. 
This binding might prevent the peptide from approaching the Asp39-His69-Ser224 catalytic triad, since $\mathbf{2 b}$ was on average $2.12 \AA$ further away from the catalytic triad than $2 \mathbf{a}$ over the entire simulation timeframe (Figures 5C, S39). Importantly, 2c did not exhibit stable binding to the pocket formed by Gly134-Gly135-Gly-136 and Gly160-Asn161-Asn162 (Movie 3, Figures 5D, S39) indicating the proteolytic protection is unique to Cys-borylation and is likely a result of placing a sterically encumbering functional group like carborane in close proximity to the polypeptide chain.

While Cys-borylation can render peptides more resistant towards proteolytic degradation, we wondered whether one can design hybrid agents with preserved binding capabilities to the protein target. To probe protein binding, we designed a model peptide (8a) containing a Ile-TyrPro sequence which was previously identified as active towards inhibiting the activity of angiotensin-converting enzyme (ACE) $)^{49}$, an important protein implicated in the regulation of blood pressure and, recently, SARS-CoV-2 infection ${ }^{50}$. Specifically, at $5 \mu \mathrm{M}$ unmodified $8 \mathbf{a}$ and Cys-borylated $\mathbf{8 b}$ were found to inhibit the activity of ACE by $24 \pm 5 \%$ and $17 \pm 4 \%$, respectively (See SI Section X). Increasing the concentration of $8 \mathbf{a}$ and $8 \mathbf{b}$ to $50 \mu \mathrm{M}$ enhanced the inhibition of ACE activity by $54 \pm 7 \%$ and $52 \pm 1 \%$, respectively (See SI Section X). The observed similarity in rates of inhibition between $\mathbf{8 a}$ and $\mathbf{8 b}$ suggests that Cys-borylation could maintain binding efficacy of the therapeutically relevant peptides while at the same time enhancing their proteolytic stability.

\section{Conclusions}

In conclusion, an organometallic strategy for borylating Cys residues within unprotected peptide sequences has been demonstrated. This work significantly expands our fundamental ability 
to construct new bioconjugates via a Cys residue by introducing a new room-temperature boronsulfur forming pathway in unprotected peptides. Importantly, Cys-borylation can engender stable hybrid peptides featuring unique recognition and binding properties towards a macrocyclic sugar as well as render the resulting peptides more proteolytically stable while maintaining their binding affinity towards a protein target. This work further demonstrates the growing importance of organometallic chemistry in the field of bioconjugation, where a designer post-translational synthetic modification can forge a chemoselective delivery of a sterically encumbering, abiotic functional group (e.g., carborane) directly to a native amino acid residue in a complex biomolecule.

\section{Data Availability}

Data supporting the results and conclusions are available within the paper and the Supplementary Information (SI).

\section{Acknowledgements}

This work was supported by the National Institutes of Health (NIH) Maximizing Investigators Research Award (MIRA, R35GM124746). A. M. S. is a Research Corporation for Science Advancement (RCSA) Cottrell Scholar and a Dreyfus Foundation Camille Dreyfus Teacher Scholar. Authors thank Mr. Nicholas Bernier for assistance with ICP-AE experiments.

\section{Contributions}

A. M. S. conceived and supervised the project. M. A. W. and A. M. S. designed the experiments. M. A. W. performed the majority of experimental work with the assistance of J. M. S. E. H. M. and L. M. A. S. contributed to the design and execution of early proof-of-concept experiments. P. 
K. and A. Z. designed and performed computational modeling experiments. M. A. W., A. M. S., J. M. S., A. Z. and P. K. analyzed the data and contributed to manuscript writing.

\section{Corresponding Authors}

Correspondence to Petr A. Král (pkral@uic.edu) and Alexander M. Spokoyny (E-mail: spokoyny@chem.ucla.edu).

\section{Competing Interests}

The authors declare no competing interest.

\section{References}

1. Hermanson, G. T. Bioconjugate Techniques $3^{\text {rd }}$ edn (Elsevier, 2013).

2. Recent representative review on general methods: Boutureira, O. \& Bernardes, G. J. L. Advances in Chemical Protein Modification. Chem. Rev. 115, 2174-2195 (2015).

3. Lavis, L. D. Teaching Old Dyes New Tricks: Biological Probes Built from Fluoresceins and Rhodamines. Annu. Rev. Biochem. 86, 825-43 (2017).

4. Li, Y. Commonly Used Tag Combinations for Tandem Affinity Purification. Biotechnol. Appl. Biochem. 55, 73-83 (2010).

5. Liu, H., Bolleddula, J., Nichols, A., Tang, L., Zhao, Z. \& Prakash, C. Metabolism of Bioconjugate Therapeutics: Why, When and How? Drug Metab. Rev. 52, 66-124 (2020).

6. Acar, H., Ting, J. M., Srivastava, S. LaBelle, J. L. \& Tirrell, M. V. Molecular Engineering Solutions for Therapeutic Peptide Delivery. Chem. Soc. Rev. 46, 6553-6569 (2017). 
7. Chalker, J. M., Bernardes, G. J. L., Lin, Y. A. \& Davis, B. G. Chemical Modification of Proteins at Cysteine: Opportunities in Chemistry and Biology. Chem. Asian J. 4, 630-640 (2009).

8. Masri, M. S. \& Friedman, M. Protein Reactions with Methyl and Ethyl Vinyl Sulfones. $J$. Protein Chem. 7, 49-54 (1988).

9. Morales-Sanfrutos, J., Lopez-Jaramillo, J., Ortega-Muñoz, M., Megia-Fernandez, A., Perez-Balderas, F., Hernandez-Mateo, F. \& Santoyo-Gonzales, F. Vinyl Sulfone: a Versatile Function for Simple Bioconjugation and Immobilization. Org. Biomol. Chem. 8, 667-675 (2010).

10. Spokoyny, A. M., Zou, Y., Ling, J. J., Yu, H., Lin, Y.-S. \& Pentelute, B. L. A PerfluoroarylCysteine $\mathrm{S}_{\mathrm{N}} \mathrm{Ar}$ Chemistry Approach to Unprotected Peptide Stapling. J. Am. Chem. Soc. 135, 5946-5949 (2013).

11. Kalhor-Monfared, S., Jafari, M. R., Patterson, J. T., Kitov, P. I., Dwyer, J. J., Nuss, J. M. \& Derda, R. Rapid Biocompatible Macrocyclization of Peptides with Decafluorodiphenylsulfone. Chem. Sci. 7, 3785-3790 (2016).

12. Valkevich, E. M., Guenette, R. G., Sanchez, N. A., Chen, Y.-C., Ge, Y. \& Strieter, E. R. Forging Isopeptide Bonds Using Thiol-Ene Chemistry: Site-Specific Coupling of Ubiquitin Molecules for Studying the Activity of Isopeptidases. J. Am. Chem. Soc. 134, 6916-6919 (2012).

13. Conte, M. L., Staderini, S., Marra, A., Sanchez-Navarro, M., Davis, B. G. \& Dondoni, A. Multi-molecule Reaction of Serum Albumin Can Occur Through Thiol-yne Coupling. Chem. Commun. 47, 11086-11088 (2011). 
14. Bottecchia, C., Rubens, M., Gunnoo, S. B., Hessel, V., Madder, A. \& Noël, T. VisibleLight-Mediated Selective Arylation of Cysteine in Batch and Flow. Angew. Chem., Int. Ed. 56, 12702-12707 (2017).

15. Vara, B. A., Li, X., Berritt, S., Walters, C. R., Petersson, E. J. \& Molander, G. A. Scalable Thioarylation of Unprotected Peptides and Biomolecules Under Ni/Photoredox Catalysis. Chem. Sci. 9, 336-344 (2018).

16. Chan, A. O.-Y., Tsai, J. L.-L., Lo, V. K.-Y., Li, L.-G., Wong, M.-K. \& Che, C.-M. Goldmediated Selective Cysteine Modification of Peptides Using Allenes. Chem. Commun. 49, $1428-1430$ (2013).

17. Vinogradova, E. V., Zhang, C., Spokoyny, A. M., Pentelute, B. L. \& Buchwald, S. L. Organometallic Palladium Reagents for Cysteine Bioconjugation. Nature 526, 687-691 (2015).

18. Kung, K. K.-Y., Ko, H.-M., Cui, J.-F., Chong, H.-C., Leung, Y.-C. \& Wong, M.-K. Cyclometalated Gold(III) Complexes for Chemoselective Cysteine Modification via Ligand Controlled C-S Bond-forming Reductive Elimination. Chem. Commun. 50, 11899$11902(2014)$.

19. Messina, M. S., Stauber, J. M., Waddington, M. A., Rheingold, A. L., Maynard, H. D. \& Spokoyny, A. M. Organometallic Gold(III) Reagents for Cysteine Arylation. J. Am. Chem. Soc. 140, 7065-7069 (2018).

20. Yang, Z., Zhong, M., Ma, X., Nijesh, K., De, S., Parameswaran, P. \& Roesky, H. W. An Aluminum Dihydride Working as a Catalyst in Hydroboration and Dehydrocoupling. $J$. Am. Chem. Soc. 138, 2548-2551 (2016). 
21. Fernández-Salas, J. A., Manzini, S. \& Nolan, S. P. Efficient Ruthenium-Catalysed S-S, SSi and S-B Bond Forming Reactions. Chem. Commun. 49, 5829-5831 (2013).

22. Romero, E. A., Peltier, J. L., Jazzar, R. \& Bertrand, G. Catalyst-free Dehydrocoupling of Amines, Alcohols, and Thiols with Pinacol Borane and 9-Borabicyclononane (9-BBN). Chem. Commun. 52, 10563-10565 (2016).

23. Rochette, É., Boutin, H. \& Fontaine, F.-G. Frustrated Lewis Pair Catalyzed S-H Bond Borylation. Organometallics 36, 2870-2876 (2017).

24. Al-Shuaeeb, R. A. A., Kolodych, S., Koniev, O., Delacroix, S., Erb, S., Nicoläy, S., Cintrat, J.-C., Brion, J., Cianférani, S., Alami, M., Wagner, A. \& Messaoudi, S. PalladiumCatalyzed Chemoselective and Biocompatible Functionalization of Cysteine-Containing Molecules at Room Temperature. Chem. Eur. J. 22, 11365-11370 (2016).

25. Willwacher, J., Raj, R., Mohammed, S. \& Davis, B. G. Selective Metal-Site-Guided Arylation of Proteins. J. Am. Chem. Soc. 138, 8678-8681 (2016).

26. Hanaya, K., Ohata, J., Miller, M. K., Mangubat-Medina, A. E., Swierczynski, M. J., Yang, D. C., Rosenthal, R. M., Popp, B. V. \& Ball, Z. T. Rapid Nickel(II)-Promoted Cysteine SArylation with Arylboronic Acids. Chem. Commun. 55, 2841-2844 (2019).

27. Scholz, M. \& Hey-Hawkins, E. Carbaboranes as Pharmacophores: Properties, Synthesis, and Application Strategies. Chem. Rev. 111, 7035-7062 (2011).

28. Leitao, E. M., Jurca, T. \& Manners, I. Catalysis in Service of Main Group Chemistry Offers a Versatile Approach to $p$-Block Molecules and Materials. Nature Chem. 5, 817-829 (2013). 
29. Keener, M., Hunt, C., Carroll, T. G., Kampel, V., Dobrovetsky, R., Hayton, T. W. \& Ménard, G. Redox-Switchable Carboranes for Uranium Capture and Release. Nature 577, 652-655 (2020).

30. Fisher, S. P., Tomich, A. W., Lovera, S. O., Kleinsasser, J. F., Guo, J., Asay, M. J., Nelson, H. M. \& Lavallo, V. Nonclassical Applications of closo-Carborane Anions: From Main Group Chemistry and Catalysis to Energy Storage. Chem. Rev. 119, 8262-8290 (2019).

31. Quan, Y. \& Xie, Z. Controlled Functionalization of $o$-Carborane via Transition Metal Catalyzed B-H Activation. Chem. Rev. 48, 3660-3673 (2019).

32. Lin, F., Yu, J.-L., Shen, Y., Zhang, S.-Q., Spingler, B., Liu, J., Hong, X. \& Duttwyler, S. Palladium-Catalyzed Selective Five-Fold Cascade Arylation of the 12-Vertex Monocarborane Anion by B-H Activation. J. Am. Chem. Soc. 140, 13798-13807 (2018).

33. Yin, Y., Ochi, N., Craven, T. W., Baker, D., Takigawa, N. \& Suga, H. De Novo CarboraneContaining Macrocyclic Peptides Targeting Human Epidermal Growth Factor Receptor. $J$. Am. Chem. Soc. 141, 19193-19197 (2019).

34. Saleh, L. M. A., Dziedzic, R. M., Khan, S. I. \& Spokoyny, A. M. Forging Unsupported Metal-Boryl Bonds with Icosahedral Carboranes. Chem. Eur. J. 22, 8466-8470 (2016).

35. Pearson, R. G. The Principle of Maximum Hardness. Acc. Chem. Res. 26, 250-255 (1993).

36. Dedon, P. C. \& Borch, R. F. Characterization of the Reactions of Platinum Antitumor Agents with Biologic and Nonbiologic Sulfur-Containing Nucleophiles. Biochem. Pharmacol. 36, 1955-1964 (1987).

37. Machen, T. E. \& Paradiso, A. M. Regulation of Intracellular pH in the Stomach. Ann. Rev. Physiol. 49,19-33 (1987). 
38. Ro, H.-A. \& Carson, J. H. pH Microdomains in Oligodendrocytes. J. Biol. Chem. 279, 37115-37123 (2004).

39. Forman, H. J., Zhang, H. \& Rinna, A. Glutathione: Overview of its Protective Roles, Measurement, and Biosynthesis. Mol. Aspects Med. 30, 1-12 (2009).

40. Hartmann, J. T. \& Lipp, H. Toxicity of Platinum Compounds. Expert Opin. Pharmacol. 6, 889-901 (2003).

41. Yang, A., Ha, S., Ahn, J., Kim, R., Kim, S., Lee, Y., Kim, J., Söll, D., Lee, H.-Y. \& Park, H.-S. A Chemical Biology Route to Site-Specific Authentic Protein Modifications. Science 354, 623-626 (2016).

42. Wright, T. H., Bower, B. J., Chalker, J. M., Bernardes, G. J. L., Wiewiora, R., Ng, W.-L., Raj, R., Faulkner, S., Vallée, M. R. J., Phanumartwiwath, A., Coleman, O. D., Thézénas, M.-L., Khan, M., Galan, S. R. G., Lercher, L., Schombs, M. W., Gerstberger, S., PalmEspling, M. E., Baldwin, A. J., Kessler, B. M., Claridge, T. D. W., Mohammed, S. \& Davis, B. G. Posttranslational Mutagenesis: A Chemical Strategy for Exploring Protein SideChain Diversity. Science 354, aag1465-1 - aag1465-11 (2016).

43. Singh, M., Sharma, R. \& Banerjess, U.C. Biotechnological Applications of Cyclodextrins. Biotechnol. Adv. 20, 341-359 (2002).

44. Assaf, K. I. \& Nau, W. M. The Chaotropic Effect as an Assembly Motif in Chemistry. Angew. Chem., Int. Ed. 57, 13968-13981 (2018).

45. Sadrerafi, K., Moore, E. E. \& Lee, M. W. Association Constant of $\beta$-cyclodextrin with Carboranes, Adamantane, and Their Derivatives Using Displacement Binding Technique. J. Incl. Phenom. Macrocycl. Chem. 83, 159-166 (2015). 
46. Ebeling, W., Hennrich, N., Klockow, M., Metz, H., Orth, H. D. \& Lang, H. Proteinase K From Tritirachium Album Limber. Eur. J. Biochem. 47, 91-97 (1974).

47. Wolfs, W.M., Bajorath, J., Muller, A., Raghunathan, S., Singh, T. P., Hinrichs, W. \& Saenger, W. Inhibition of Proteinase $\mathrm{K}$ by Methoxysuccinyl-Ala-Ala-Pro-AlaChloromethyl Ketone. J. Biol. Chem. 266, 17695-17699 (1991).

48. Fanfrlík, J., Lepšík, M., Horinek, D., Havlas, Z. \& Hobza, P. Interaction of Carboranes with Biomolecules: Formation of Dihydrogen Bonds. ChemPhysChem 7, 1100-1105 (2006).

49. Kohmura, M., Nio, N., Kubo, K., Minoshima, Y., Munekata, E. \& Ariyoshi, Y. Inhibition of Angiotensin-Coverting Enzyme by Synthetic Peptides of Human $\beta$-Casein. Agric. Biol. Chem. 53, 2107-2114 (1989).

50. Ghafouri-Farda, S., Noroozib, R., Omrania, M. D., Branickib, W., Pośpiechb, E., Sayada, A., Pyrcb, K., Łabajb, P. P., Vafaeec, R., Taherid, M. \& Sanak, M. Angiotensin Converting Enzyme: A review on Expression Profile and its Association with Human Disorders with Special Focus on SARS-CoV-2 Infection. Vascul. Pharmacol., 130, 106680 (2020). 